\title{
Molecular and phenotypic characterization of methicillin-resistant Staphylococcus aureus isolates from a tertiary hospital in the Philippines
}

\author{
Demetrio L. Valle Jr. ${ }^{1,2}$, Phyllis Anne P. Paclibare ${ }^{1,3}$, Esperanza C. Cabrera ${ }^{4}$ and Windell L. Rivera ${ }^{1,3^{*}}$
}

\begin{abstract}
Background: Methicillin-resistant Staphylococcus aureus (MRSA) poses a major threat to public health worldwide. There are relatively few studies addressing the molecular epidemiology of MRSA in the Philippines.

Methods: This study characterized MRSA isolates in terms of their antimicrobial susceptibility profile, the SCCmec type, and the presence of lukF-lukS genes for Panton-Valentine leukocidin (PVL) and determined the relatedness of the isolates by random amplified polymorphic DNA (RAPD)-polymerase chain reaction (PCR).

Results: A total of 236 S. aureus were isolated from clinical specimens of the Makati Medical Center in Makati City, Philippines, between January 2013 and June 2013, and 108 or $45.76 \%$ were found to be MRSA. Results showed that the MRSA strains were resistant to trimethoprim-sulfamethoxazole (20.37\%), azithromycin (10.19\%), gentamicin (5.56 \%), and linezolid (4.63\%), while all were susceptible to vancomycin, nitrofurantoin, levofloxacin, minocycline, rifampin, and tetracycline. One isolate was found positive for inducible clindamycin resistance. All of the 108 MRSA strains were confirmed to carry the mecA and SCCmec genes, while the PVL genes were detected in 41 (38 \%) of the isolates. Ninety-six isolates (89\%) carried SCCmec type IV, while the remaining isolates carried SCCmec type I (11 isolates) or type III (one isolate).

Conclusion: This study is the first to present a comprehensive MRSA surveillance data with molecular characterization in a tertiary hospital in the Philippines.
\end{abstract}

Keywords: Staphylococcus aureus, Methicillin-resistant S. aureus (MRSA), SCCmec, Panton-Valentine leukocidin (PVL), Phylogram, Random amplified polymorphic DNA (RAPD), Philippines

\section{Background}

Staphylococcus aureus is the most potent and significant species of staphylococci that causes infections from simple furuncles (boils) and carbuncles to deadly necrotizing pneumonia and toxic shock syndrome [1]. It causes considerable morbidity and mortality in both healthcare and community settings despite enormous advances in medical care. In the 1960s, an S. aureus strain resistant to the then newly introduced antibiotic methicillin, thus called methicillin-resistant S. aureus (MRSA), emerged as a significant pathogen in hospitals and intensive care

\footnotetext{
* Correspondence: wlrivera@science.upd.edu.ph

${ }^{1}$ Institute of Biology, College of Science, University of the Philippines,

Diliman, Quezon City 1101, Philippines

${ }^{3}$ Natural Sciences Research Institute, University of the Philippines, Diliman,

Quezon City 1101, Philippines

Full list of author information is available at the end of the article
}

units, especially in crowded facilities [2, 3]. Since then, MRSA strains have developed resistance to a variety of other antimicrobial agents and are the principal causes of hospital-acquired infections worldwide [4].

Methicillin is a $\beta$-lactam antibiotic that is resistant to the action of $\beta$-lactamase secreted by many penicillinresistant bacteria [5]. It acts via competitive inhibition of transpeptidase enzyme by its affinity to penicillinbinding protein 2 (PBP2) used by bacteria to cross-link the peptide (D-alanyl-alanine) mandatory for peptidoglycan synthesis. It was developed to treat staphylococcal infections. Resistance to methicillin is developed due to acquiring a penicillin-binding protein 2A (PBP2A) encoded by the mecA gene from a mobile "staphylococcal cassette chromosome (SCC) mec." As of 2009, 11 types of SCCmec, which differ in the combination of the 
type of $\mathrm{ccr}$ gene complex and the class of mec gene complex present in the cassette, have been identified in $S$. aureus and in Staphylococcus epidermidis [4, 6]. The current diagnosis for MRSA includes resistance to either oxacillin or cefoxitin, which indicate non-susceptibility to all categories of $\beta$-lactams and cephamycins, except anti-MRSA cephalosporins [7].

MRSA infections have been acknowledged for several years as either healthcare-associated (HA-MRSA) or community-acquired (CA-MRSA) [8, 9]. Unlike the HAMRSA, it is alarming that CA-MRSA infections are common in healthy individuals with no or partial exposure to healthcare facilities and in a variety of populations, which include the prisoners, children, adolescents, and athletes [10]. Outbreak and in-depth analysis of CAMRSA were first reported by Udo et al. [11] among indigenous Australians in Western Australia without any healthcare contacts. CA-MRSA generally causes soft tissue and primary skin infections. Furthermore, CAMRSA abscess outbreaks were reported among people in closed living communities like jail inmates, military recruits, football players, and homosexual men $[12,13]$.

CA-MRSA strains were shown to have distinctive genetic makeup, antimicrobial profiles, and virulence properties that set them apart from HA-MRSA strains [14]. The strong relationship between CA-MRSA and PantonValentine leukocidin (PVL) is demonstrated by the presence of the genes lukF-lukS only in CA strains [15]. PVL is an exotoxin that acts by destroying the leukocytes via formation of pores which causes higher cation permeability of the cell membrane. It is usually present in USA 300 and USA 400 strains and harbored by SCCmec IVcontaining strains [16]. PVL is known to induce necrosis and is associated with necrotizing pneumonia, furunculosis, cutaneous abscess, soft tissues, and invasive skin infections [13, 17, 18]. However, for the past decade, $\mathrm{HA} / \mathrm{CA}$ distinctions have not been consistent as CA strains become "domesticated" to the healthcare settings [19] and HA strains become "feral" and establish in the community [20]. Due to the molecular variation of MRSA, some authors have suggested that antimicrobial susceptibility may continue to be a distinguishing trait of CA-MRSA [21].

Many phenotypic and molecular techniques are available to differentiate MRSA isolates. The most common phenotypic method is antimicrobial susceptibility testing (AST); however, isolates with different genetic profiles may have the same antibiogram patterns [22]. This limitation of phenotypic methods has elicited the development of molecular or DNA-based procedures, including restriction fragment length polymorphism (RFLP) analysis, ribotyping, binary typing, and PCR-based methods [23-26]. For long-term and broad epidemiological studies of MRSA, a number of research deal with either multilocus sequence typing (MLST) or pulse-field gel electrophoresis (PFGE) [22, 27]. These methods allow for simultaneous amplification of multiple regions of the DNA resulting in distinct patterns, in contrast to other targeted techniques such as staphylococcal protein A (spa) or direct repeat unit (dru) typing [28]. However, MLST is costly, lengthy, and labor intensive for clinical use while PFGE is subjected to biased interpretation in comparing patterns and fingerprint images [22].

Another useful method is random amplified polymorphic DNA (RAPD) typing, which is based on the genomic DNA amplification using a single short oligonucleotide primer of arbitrary or random sequence [29]. PCR products are varied due to random hybridization of primers with DNA sequences that vary among strains [30]. Due to its versatility, easy procedure, and high level of discrimination, RAPD is widely used in epidemiological studies of HA-MRSA [31]. It is critical to have a precise epidemiological typing of MRSA so that it would be easier to control the spread of infection and track epidemics despite the inherent variation of strains. The challenge today is to keep on making bacterial databases linking genetic markers and clinical outcomes so that important correlations of the disease can be detected. This study then aimed to investigate the molecular diversity of MRSA isolates obtained from out- and inpatients of Makati Medical Center in Makati City, Philippines, between January 2013 and June 2013 using RAPD.

\section{Methods}

\section{Bacterial isolates}

This study included all clinical isolates submitted for culture and sensitivity at the Department of Pathology and Laboratories, Makati Medical Center, from January 1, 2013 to June 30, 2013. S. aureus isolates were identified using Vitek 2 (bioMérieux, Marcy-l'Etoile, France) GP colorimetric identification card. Resistance to oxacillin or cefoxitin was confirmed by Vitek 2 AST-GP67-22226 (bioMérieux, Marcy-l'Etoile, France), with resistance defined as oxacillin minimum inhibitory concentration $(\mathrm{MIC}) \geq 4 \mu \mathrm{g} / \mathrm{ml}$ and cefoxitin MIC $\geq 8 \mu \mathrm{g} / \mathrm{ml}$. Staph MRSA $^{\text {TM }}$ latex agglutination test (bioMérieux, Marcyl'Etoile, France) was performed for PBP2A determination. In the case of multiple $S$. aureus isolates from the same patient, the first detected resistant specimen was included in the study. The isolates were stored at $-80^{\circ} \mathrm{C}$ and were subcultured on nutrient agar slants prior to DNA extraction.

\section{Antimicrobial susceptibility testing}

In addition to oxacillin and cefoxitin, other antimicrobials listed for routine reporting for $S$. aureus were included for AST using Vitek 2 AST-GP67-22226 (bioMérieux, Marcy- 
l'Etoile, France) test card for Gram-positive susceptibility. The MIC interpretive standard or breakpoint values were set following the guidelines of Clinical and Laboratory Standard Institute M100-S23 [32]. S. aureus ATCC 25923 was included as control. Isolates resistant to erythromycin and susceptible to clindamycin were screened for inducible clindamycin resistance using modified disk diffusion test or D-zone test.

\section{DNA extraction}

Genomic DNA from MRSA isolates was extracted following the rapid boiling method described by Zhang et al. [33]. One to five isolated colonies from a nutrient agar (NA) plate were suspended in $50 \mu \mathrm{l}$ sterile water and heated at $99^{\circ} \mathrm{C}$ for $10 \mathrm{~min}$. The suspension was pelleted by centrifugation at $20,000 \times g$ at $4{ }^{\circ} \mathrm{C}$. The supernatant was collected and stored at $-20{ }^{\circ} \mathrm{C}$ until further use. DNA yield was confirmed by NanoDrop ${ }^{\text {th }}$ spectrophotometry prior to PCR-based assays.

\section{PCR amplification of mecA and PVL genes}

Multiplex PCR assay for the simultaneous identification of mecA, lukF-lukS, and 16S ribosomal RNA (rRNA) genes was performed following the method described by Zhang et al. [33] and McClure et al. [34]. Amplification of $16 \mathrm{~S}$ rRNA served as an internal control to rule out any amplification inhibitors. Other targets include mecA, which is a determinant of MRSA, and lukF-lukS, which encodes the $\mathrm{F}$ and $\mathrm{S}$ biocomponent proteins of PVL. The primers are listed in Table 1 . The thermocycling conditions were based on McClure et al. [34] with a final extension modification at $72{ }^{\circ} \mathrm{C}$ for $10 \mathrm{~min}$. PCR-based products in the entire study were separated in $1.8 \%$ agarose gel and were analyzed using UV transilluminator after staining with ethidium bromide.

\section{PCR amplification of SCCmec type}

All isolates were subjected for multiplex PCR for the detection of six SCCmec types (I, IA, II, III, IV, IVA) based on loci located upstream and downstream of the mecA gene as described by Zetola et al. [35]. The primer sequences are given in Table 2 . The $m e c A$ gene was included

Table 1 Primers for the detection of mecA, lukF-lukS, and 16S rDNA for Staphylococcus aureus

\begin{tabular}{lll}
\hline Primer & Nucleotide sequence $\left(5^{\prime}\right.$ to $\left.3^{\prime}\right)$ & $\begin{array}{l}\text { Product size } \\
(\mathrm{bp})\end{array}$ \\
\hline Staph 756F & AACTCTGTTATTAGGGAAGAACA & 756 \\
Staph 750R & CCAACCTTCCTCCGGTTTGTCACC & \\
Luk-PV-1 & ATCATTAGGTAAAATGTCTGGACATGATCCA & 433 \\
Luk-PV-2 & GCATCAAGTGTATTGGATAGCAAAAGC & \\
MecA1 & GTAGAAATGACTGAACGTCCGATAA & 310 \\
MecA2 & CCAATTCCACATTGTTCGGTCTAA & \\
\hline
\end{tabular}

to serve as internal control. The multiplex PCR was performed following the method of Cabrera et al. [12].

\section{Random amplified polymorphic DNA typing and analysis} RAPD typing was performed following the method described by Casey et al. [36] utilizing the 10-mer primer 5'-AGC GTC ACT G-3', with few modifications. The primer has been used in characterizing strains of $S$. aureus [36, 37]. DNA sizing and quantifications were done using Agilent 2100 bioanalyzer (Agilent technologists, USA). RAPD fingerprints were analyzed using the Sequentix-Digital DNA Processing (Germany). The lanes of the gel images were extracted using GelQuest (Sequentix, Germany) and were transformed into a trace data curve. Peaks were compared with base sizes from 110 to $1000 \mathrm{bp}$, and hyperbin width was $10 \mathrm{bp}$. The following parameters were taken: base sizes, peak heights, areas, and area-to-height ratio, and a hyperbin table (01matrix) was obtained, which can be used for binary analysis using ClusterVis (Sequentix, Germany). The Jaccard distance measure was used for cluster analysis. The Jaccard coefficient (or similarity) is calculated from datasets where the presence and absence of characters between two or more samples are compared. Such a dataset consists of $1 \mathrm{~s}$ for the presence of a certain character in a sample and 0 s for the absence of a character which is also called a binary matrix. The resulting distance matrix was analyzed using the neighbor-joining (NJ) algorithm. Three S. aureus strains (SA, Sab, and SAc) were used as controls, while two Escherichia coli samples (EC and $\mathrm{ECb})$ were used as outgroup for rooting the tree. The bacterial genetic relationships are shown graphically as a phylogram to show the topology and the real distances between the samples.

\section{Results}

\section{Study population and prevalence of MRSA}

Of the 236 S. aureus isolates, 108 were found to be MRSA $(45.76 \%)$. Patients were from ages 5 months to 100 years old, and the mean age was $36.9 \pm 22.4$ (mean \pm SD) years. The MRSA-positive subjects included 66 (61.1\%) males and $42(38.9 \%)$ females. Isolates were collected from 66 outpatients (61.1\%) and 42 inpatients (38.9\%). Among the 42 inpatients, 21 (50\%) were identified with clinical infections within $48 \mathrm{~h}$ of hospital admission. The MRSA isolates were from the skin, wound, superficial abscess (79 cases), respiratory tract specimens (14 cases), blood (6 cases), ear/eye discharge (4 cases), and deep abscess (5 cases).

\section{Antimicrobial susceptibility pattern}

The antimicrobial susceptibility patterns of all MRSA isolates are summarized in Table 3. As expected, all MRSA isolates were resistant to the B-lactams penicillin, oxacillin, and cefoxitin. Resistance was not observed in 
Table 2 Primers for the determination of SCCmec type of MRSA isolates

\begin{tabular}{|c|c|c|c|}
\hline Primer & Nucleotide sequence ( $5^{\prime}$ to $3^{\prime}$ ) & Product size (bp) & scCmec type/region \\
\hline CIF2 F2 & TTCGAGTTGCTGATGAAGAAGG & 495 & $\mathrm{I}, \mathrm{IA}$ \\
\hline CIF2 R2 & ATTTACCACAATTACTACCAGC & & \\
\hline KDP F1 & AATCATCTGCCATTGGTGATGC & 284 & $\|$ \\
\hline KDP R1 & CGAATGAAGTGAAAGAAAGTGG & & \\
\hline DCS F2 & CATCCTATGATAGCTTGGTC & 342 & I, IA, II, IV, IVA \\
\hline DCS R2 & CTAAATCATAGCCATGACCG & & \\
\hline RIF4 F3 & GTGATTGTTCGAGATATGTGG & 243 & III \\
\hline RIF4 R9 & CGCTTTATCTGTATCTATCGC & & \\
\hline IS431 P4 & CAGGTCTCTTCAGATCTACG & 381 & IA, II, IVA \\
\hline PUB110 R1 & GAGCCATAAACACCAATAGCC & & \\
\hline MECA P4 & TCCAGATTACAACTTCACCAGG & 162 & mecA gene \\
\hline MECA P7 & CCACTTCATATCTTGTAACG & & \\
\hline
\end{tabular}

tetracycline, minocycline, rifampin, and vancomycin. For the rest of the antimicrobials, resistance was low. The susceptibility of the isolates to vancomycin and linezolid was also expected as these drugs are currently effective against MRSA.

\section{Detection of $16 \mathrm{~S}$ rRNA, mecA, and PVL genes}

Both the internal control 16S rRNA for Staphylococcus spp. and mecA genes were present in all MRSA isolates. Of the 108 MRSA isolates investigated, 41 (38.0\%) were positive for PVL genes. Table 4 shows the distribution of the PVL genes among different types of clinical samples. Twenty-four $(58.5 \%)$ cases were from outpatients and 17 (41.5\%) cases were from inpatients. The other samples positive for PVL genes include wound; wound

Table 3 Antimicrobial susceptibility profile of MRSA isolates

\begin{tabular}{llll}
\hline Antimicrobial & Susceptible & Intermediate & Resistant \\
\hline Penicillin & 0 & 0 & $108(100 \%)$ \\
Oxacillin & 0 & 0 & $108(100 \%)$ \\
Cefoxitin & 0 & 0 & $108(100 \%)$ \\
Ciprofloxacin & $100(92.59 \%)$ & $4(3.70 \%)$ & $4(3.7 \%)$ \\
Levofloxacin & $99(91.67 \%)$ & $9(8.33 \%)$ & 0 \\
Clindamycin & $99(91.67 \%)$ & $6(5.56 \%)$ & $3(2.78 \%)$ \\
Erythromycin & $102(94.44 \%)$ & $3(2.78 \%)$ & $3(2.78 \%)$ \\
Gentamicin & $102(94.44 \%)$ & 0 & $6(5.56 \%)$ \\
Minocycline & $108(100 \%)$ & 0 & 0 \\
Tetracycline & $108(100 \%)$ & 0 & 0 \\
Vancomycin & $108(100 \%)$ & 0 & 0 \\
Azithromycin & $86(79.63)$ & $11(10.19 \%)$ & $11(10.19 \%)$ \\
Nitrofurantoin & $54(50.00 \%)$ & $54(50.00 \%)$ & 0 \\
TMP-SXT & $82(75.93 \%)$ & $4(3.70 \%)$ & $22(20.37 \%)$ \\
Rifampin & $108(100 \%)$ & 0 & 0 \\
Linezolid & $103(95.37 \%)$ & 0 & $5(4.63 \%)$ \\
\hline
\end{tabular}

discharge; abscess; respiratory tract samples; blood; bile; and eye, mouth, and ear discharge. It was noted that isolates from two patients who died from septicemia were found to be positive for PVL.

\section{Determination of SCCmec type}

Ninety-six out of the 108 MRSA isolates (89\%) carried SCCmec type IV. Eleven isolates carried SCCmec type I, only one carried SCCmec type III, and none for type II. The majority of the MRSA strains came from a variety of samples. The SCCmec type I strains were isolated from wound, blood samples, and tracheal aspirates, while the type III strain came from a thigh abscess. Figure 1 shows the distribution of the detected SCCmec types among different sample types. Aside from the majority (39/41) of PVL carriers among the type IV, 2 PVL carriers belong to type I, both from blood samples.

\section{RAPD analysis}

RAPD typing yielded 1-6 distinct bands per isolate, revealing DNA markers ranging from 100 to $7000 \mathrm{bp}$. The phylogram (Fig. 2) obtained resulted in two main groups, group I and group II, which further branched into two main clusters (A and B). The two E. coli samples (EC and $\mathrm{ECb}$ ) are reference strains and were used as outgroup for rooting the tree. Group I has only one

Table 4 Carriage of the PVL genes lukF-lukS among MRSA isolates

\begin{tabular}{llll}
\hline Clinical sample & Outpatient & Inpatient & Total \\
\hline $\begin{array}{l}\text { Wound, wound discharge, } \\
\text { abscess }\end{array}$ & $22(91.6 \%)$ & $11(64.7 \%)$ & $33(80.4 \%)$ \\
Respiratory tract & $1(4.2 \%)$ & $1(5.9 \%)$ & $2(4.9 \%)$ \\
Blood, bile & $1(4.2 \%)$ & $3(17.6 \%)$ & $4(9.8 \%)$ \\
Eye, mouth, ear discharge & 0 & $2(11.8 \%)$ & $2(4.9 \%)$ \\
Total & $24(58.5 \%)$ & $17(41.5 \%)$ & 41 \\
\hline
\end{tabular}




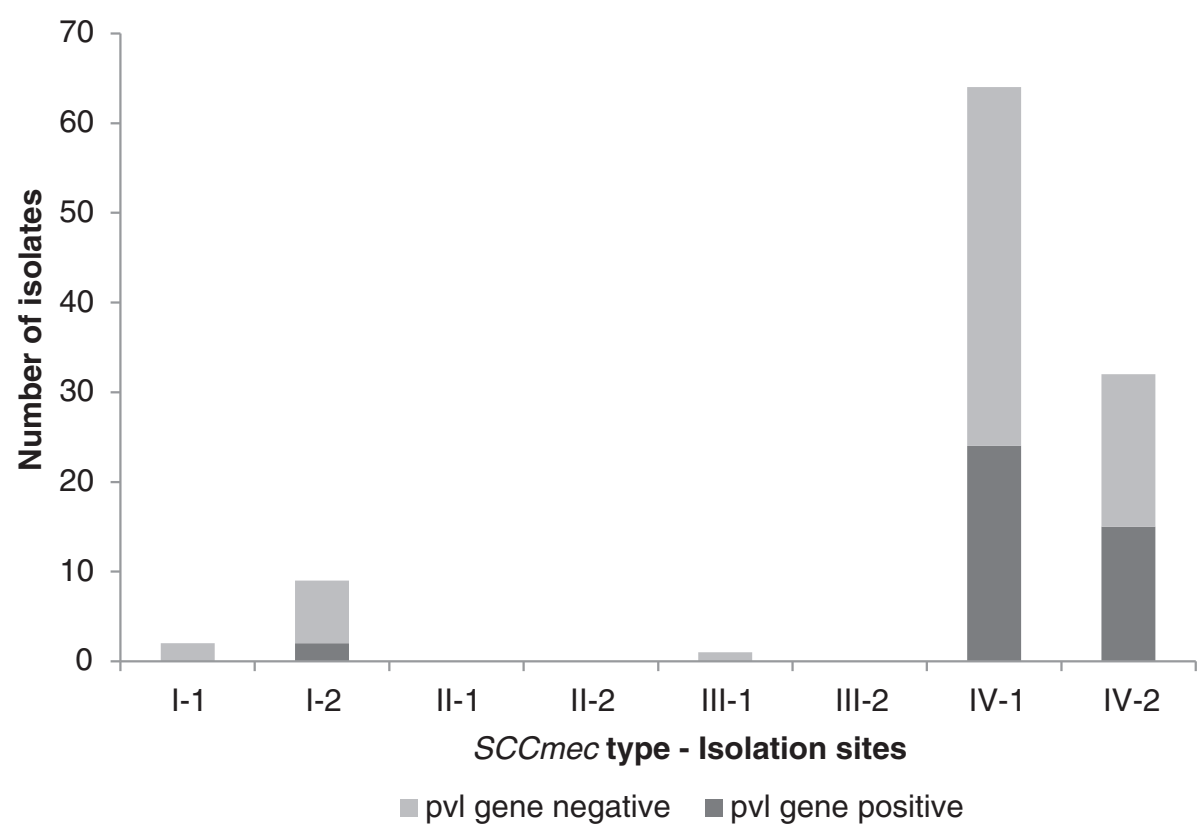

Fig. 1 Prevalence of SCCmec types at the Makati Medical Center from January to June 2013. Isolation type 1 denotes samples isolated from outpatients while 2 is samples isolated from inpatients. I, II, III, and IV mean SCCmec types I, II, III, and IV, respectively

isolate (Isolate 54). Isolate 54 is distinct from all the other isolates since it is the only isolate with just a single prominent band. Isolate 54 was taken from a wound discharge from an outpatient. It is one of the two isolates with SCCmec type I from outpatients and does not carry the PVL genes. Group II cluster A consisted of four isolates, all from patients confined in the hospital, expressing both the SCCmec type IV and the PVL genes. Group II cluster $B$ has four sub-clusters, $B_{1}, B_{2}, B_{3}$, and $B_{4}$. Sub-cluster $B_{1}$ contained 25 isolates; all of them came from outpatients with SCCmec type IV. The PVL genes were present only in four isolates, with one from an outpatient sample. The S. aureus strains (SA, Sab, and SAc) also clustered in this group as well as the triplicate samples of isolates 107 and 108. Sub-cluster $B_{2}$ is comprised of 31 isolates from both outpatients and inpatients, with 6 out of the 31 isolates that carry SCCmec type I, and one carries SCCmec type III. Of the 10 PVL gene carriers with SCCmec type IV, seven came from outpatients and three from inpatients; while two out of six SCCmec type I isolates carried the PVL genes, both from outpatients. The sub-cluster $\mathrm{B}_{3}$ also consisted of 31 isolates, including 14 PVL gene carriers with SCCmec type IV, nine from outpatients and five from inpatients, and two inpatient isolates with SCCmec type I, without the PVL genes. Finally, sub-cluster $\mathrm{B}_{4}$ contained 16 isolates, including 15 that carried SCCmec type IV and one with SCCmec type I. The PVL genes were detected in seven isolates with SCCmec type IV in this group, five from outpatients and two from inpatients. The phylogram obtained showed that the SCCmec type and PVL genes are widely distributed. Only cluster A with the smallest population showed similarities in all parameters, which include the source of sample, presence of PVL genes, and SCCmec type IV. The method produced 45 major banding patterns in total.

\section{Discussion}

This study is the first to present a comprehensive MRSA surveillance data with molecular characterization in a Philippine tertiary hospital. This current study revealed a prevalence of 108 out of 236 (45.76 \%) MRSA among clinical isolates received. This prevalence is comparable to previously reported studies from different countries, $22-57 \%$ in the USA, 43-58 \% in Italy, 54 \% in Portugal, 42-44 \% in Argentina and Paraguay, $48 \%$ in Mexico, and $44 \%$ in Greece. Lower rates were reported in other European countries, $0.5 \%$ in Iceland, $2 \%$ in Switzerland and Netherlands, and $7.8 \%$ in Italy [38-43]. In the Philippines, few studies showed lower prevalence rates, $18 \%$ in three tertiary hospitals in Manila from 1999 to 2003 and $13.6 \%$ in a medical center in Quezon City in $2001[44,45]$.

Susceptibility testing of MRSA may be challenging because of the heterogeneous resistance displayed by many isolates. In this study, resistance to trimethoprimsulfamethoxazole (SXT) was observed in 22 cases (20.37\%) from the outpatients, while no resistance was observed for tetracycline, minocycline, rifampin, and vancomycin. Contrastingly, antibiogram patterns from 


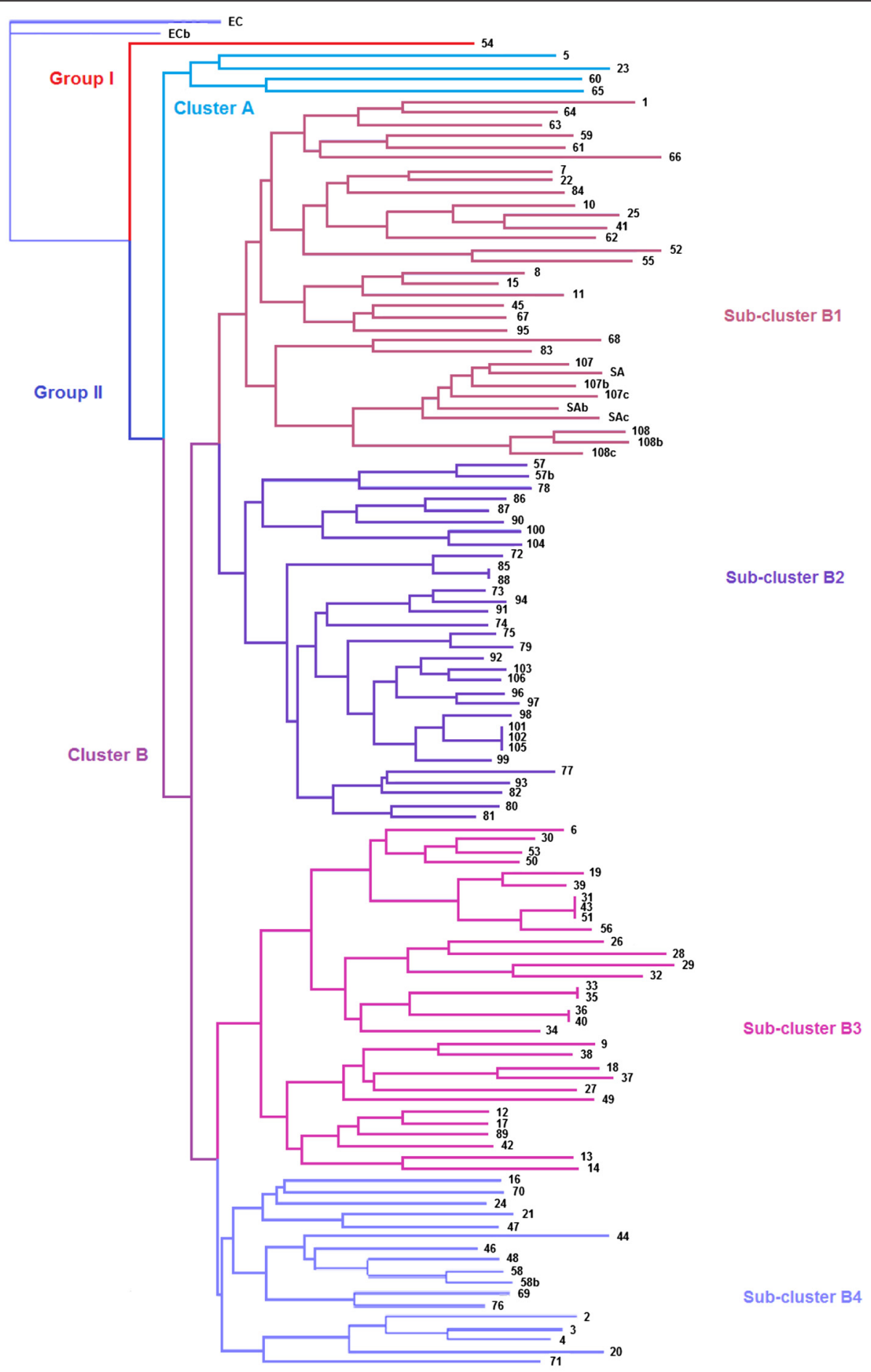

Fig. 2 Phylogram of genetic relationships between 108 isolates of S. aureus by RAPD

previous studies showed high resistance to tetracycline, clindamycin, and erythromycin and low resistance to SXT among CA-MRSA strains in Taiwan and HAMRSA strains from Czech Republic [46, 47]. High resistance to levofloxacin (98.6 \%), erythromycin (97.8\%), tetracycline (94.2\%), and rifampin (87.1\%) were also reported in China [48]. These conflicting patterns may be brought about by geographical differences 
and also by the nature of host or sample type, thus making a universal differentiation of MRSA strains a challenge. Antibiograms, however, may be important in monitoring the current and emerging resistance patterns in MRSA. While there have been reports of MRSA resistant to vancomycin and linezolid $[49,50]$, the fact that these drugs remained effective against MRSA strains evaluated in this study was reassuring.

The PVL genes, lukF-lukS, were detected in 41 cases (38.0\%) of MRSA isolates. The prevalence of the PVL genes in this study was unexpectedly higher than reported studies in other foreign hospitals. Some studies from Czech Republic, China, Trinidad and Tobago, and Austria and Hungary reported $0 \%$ prevalence of PVL genes in all confirmed MRSA isolates [47, 48, 51, 52]. PVL is a cytolytic toxin comprised of $\mathrm{F}$ and $\mathrm{S}$ subunits which are encoded by the $l u k P V$ operon, which contains the lukF-lukS genes. It forms pores exclusively in leukocytes and induces high inflammatory mediators' response such as leukotriene B4, IL-8, and histamine [53]. Presently, PVL gene-positive MRSA strains are responsible for nosocomial infections in countries where the prevalence of CA-MRSA is high such as the Philippines [12]. PVL has been thought to be a good marker for CA-MRSA since it has been reported to be high among these isolates [54]. However, it is postulated that CA-MRSA strains are now beginning to infiltrate hospital settings making it impossible to be differentiated from HA-MRSA strains. Similarly, this present study was able to detect PVL gene carriers among out- and inpatients.

Typing of MRSA isolates within the context of epidemiological investigation of nosocomial and communityacquired infections is of great significance for considering the connection and similarities of isolates, for establishing the series of infections, and, accordingly, for the application of suitable infection control and preventive measures. Clonal relatedness can only be deduced from molecular studies comparing isolates from MRSA strains. The RAPD typing done has allowed the genotyping of the S. aureus isolates. The fingerprints created by this primer revealed distinctive profiles for every strain in terms of number and banding patterns. There was a definite clustering of the isolates into at least seven large clades, which indicate that the primers have resolved the strain types into at least seven groups. Group I, group B cluster A, and sub-cluster $B_{1}$ show good distinguishing traits than the other clades. Group I separated one (Isolate 54) SCCmec type I from an external wound discharge from the rest. Then, group II cluster A included inpatient isolates only with SCCmec type IV and the PVL genes. This clade may reflect the socalled domesticated strains that circulate in community settings but might be isolated from hospital patients [55]. Sub-cluster $B_{1}$ also show clustering of non-PVL gene carriage among its members. However, it is to note that most of the isolates included here came from outpatients. The close topology of the latter clades may support the domestication of CA-MRSA strains, as these commonly lose functional PVL when infected patients remain in hospital settings for a time period [19].

The RAPD analysis in this study, however, was not able to establish the correlation of the characteristics of the isolates based on the clinical specimen source, SCCmec types, and the incidence of the PVL genes. Subclusters $\mathrm{B}_{2}, \mathrm{~B}_{3}$, and $\mathrm{B}_{4}$ contained random clustering of isolates from in- and outpatients; presence and absence of PVL genes; and a combination of SCCmec types I, III, and IV. This may be due to chance accrual of neutral mutations or to alteration of the predominant strain to adapt to constant environmental changes. Therefore, these could not be traced as either HA- or CA-MRSA. Mutations of a single strain for a period of time provide further avenues for the procurement of pathogenic features such as antimicrobial resistance, and thus, genetic distinction offers rise to broad genomic and phenotypic array [56]. Furthermore, the presence of the PVL genes did not associate with the outpatients or CA-MRSA, since only 17 of the 41 outpatients carried the gene. In addition to the possible domestication of the CA strains, the study covered a 6-month period, long enough for increasing the number of polymorphisms for such MRSA strains [55].

\section{Conclusions}

MRSA remains one of the most important threats to public health due to the fast dissemination and diversification of MRSA strains with greater virulence and antimicrobial resistance. In the Philippines, MRSA is a principal source of nosocomial infections, and the prevalence of MRSA in community-acquired infections is mounting. Categorization of these clones is significant if suitable local treatment plans are to be established. A comprehensive investigation of strains disseminating within an area may be used to evaluate the association between clonal types, disease symptoms, antimicrobial choice, and clinical outcomes. Hence, the evidence gathered from typing $S$. aureus isolates can assist the infection control teams to recognize the epidemiology of this organism in the hospitals and communities and furthermore help in the application of effective control measures, at least in Philippines.

\section{Competing interests \\ The authors declare that they have no competing interests.}

Authors' contributions

All authors read and approved the final manuscript.

\section{Acknowledgements}

We thank Pauline Dianne M. Santos and Alyzza Marie B. Calayag for the technical assistance. This study was supported by a research grant from the Philippine Council for Health Research and Development of the Department of Science and Technology. 


\section{Author details}

'Institute of Biology, College of Science, University of the Philippines, Diliman, Quezon City 1101, Philippines. ${ }^{2}$ Department of Pathology and Laboratories, Makati Medical Center, Makati City 1229, Philippines. ${ }^{3}$ Natural Sciences Research Institute, University of the Philippines, Diliman, Quezon City 1101, Philippines. ${ }^{4}$ Biology Department, De La Salle University, Taft Ave., Manila City 1004, Philippines.

\section{Received: 12 November 2015 Accepted: 15 January 2016 Published online: 14 March 2016}

\section{References}

1. Nubel U, Roumagnac $P$, Feldkamp $M$, et al. Frequent emergence and limited geographic dispersal of methicillin-resistant Staphylococcus aureus. Proc Natl Acad Sci U S A. 2008:105:14130-5.

2. Jevons MP, Coe A, Parker M. Methicillin resistance in staphylococci. Lancet 1963:281:904-7.

3. Huang H, Flynn NM, King JH, Monchaud C, Morita M, Cohen SH. Comparisons of community-associated methicillin-resistant Staphylococcus aureus (MRSA) and hospital-associated MSRA infections in Sacramento, California. J Clin Microbiol. 2006;44:2423-7.

4. Helen W, Boucher G, Corey R. Epidemiology of methicillin-resistant Staphylococcus aureus. Clin Infect Dis. 2008;46:S344-9.

5. Mitscher L. Antibiotics and antimicrobial agents. In: Williams DA, Lemke TL, editors. Foye's principles of medicinal chemistry. Philadelphia: Lippincott Williams \& Wilkins; 2002.

6. International Working Group on the Classification of Staphylococcal Cassette Chromosome Elements (IWG-SCC). Classification of staphylococca cassette chromosome mec (SCCmec): guidelines for reporting novel SCCmec elements. Antimicrob Agents Chemother. 2009;53:4961-7.

7. Magiorakos A-P, Srinivasan A, Carey RB, et al. Multidrug-resistant, extensively drug-resistant and pandrug-resistant bacteria: an international expert proposal for interim standard definitions for acquired resistance. Clin Microbiol Infect. 2012;18:268-81.

8. de Sousa MA, De Lencastre $H$. Evolution of sporadic isolates of methicillinresistant Staphylococcus aureus (MRSA) in hospitals and their similarities to isolates of community-acquired MRSA. J Clin Microbiol. 2003:41:3806-15.

9. Saiman L, Keefe MO, Graham PL, et al. Hospital transmission of communityacquired methicillin-resistant Staphylococcus aureus among postpartum women. Clin Infect Dis. 2003;37:1313-9.

10. Karchmer AW, Archer GL, Dismukes WE. Staphylococcus epidermidis causing prosthetic valve endocarditis: microbiologic and clinical observations as guides to therapy. Ann of Intern Med. 1983;98:447-55.

11. Udo E, Pearman J, Grubb W. Genetic analysis of community isolates of methicillin-resistant Staphylococcus aureus in Western Australia. J Hosp Infect. 1993:25:97-108

12. Cabrera EC, Ramirez-Argamosa DT, Rodriguez RD. Prevalence of communityacquired methicillin-resistant Staphylococcus aureus from inmates of the Manila City Jail, characterization for SCCmec type and occurrence of PantonValentine leukocidin gene. Philipp Sci Letters. 2010;3:1-5.

13. Kazakova SV, Hageman JC, Matava M, et al. A clone of methicillin-resistant Staphylococcus aureus among professional football players. N Engl J Med. 2005:352:468-75.

14. González-Domínguez M, Seral C, Sáenz Y, et al. Epidemiological features, resistance genes, and clones among community-onset methicillin-resistant Staphylococcus aureus (CO-MRSA) isolates detected in northern Spain. Int Med Microbiol. 2012:302:320-6.

15. Lina G, Piémont $Y$, Godail-Gamot F, et al. Involvement of Panton-Valentine leukocidin-producing Staphylococcus aureus in primary skin infections and pneumonia. Clin Infect Dis. 1999;29:1128-32.

16. Saïd-Salim B, Mathema B, Braughton K, et al. Differential distribution and expression of Panton-Valentine leukocidin among community-acquired methicillin-resistant Staphylococcus aureus strains. J Clin Microbiol. 2005;43: 3373-9.

17. Genestier A-L, Michallet M-C, Prévost G, et al. Staphylococcus aureus PantonValentine leukocidin directly targets mitochondria and induces Baxindependent apoptosis of human neutrophils. J Clin Invest. 2005;115:3117.

18. Montgomery CP, Daum RS. Transcription of inflammatory genes in the lung after infection with community-associated methicillin-resistant Staphylococcus aureus: a role for Panton-Valentine leukocidin? Infect Immun. 2009;77:2159-67.
19. Popovich K, Weinstein R, Hota B. Are community-associated methicillinresistant Staphylococcus aureus (MRSA) strains replacing traditional nosocomial MRSA strains? Clin Infect Dis. 2008;46:787-94.

20. Miller R, Walker A, Knox K, et al. 'Feral' and 'wild'-type methicillin-resistant Staphylococcus aureus in the United Kingdom. Epidemiol Infect. 2010;138:655-65.

21. Peterson A, Davis M, Julian K, et al. Molecular and phenotypic characteristics of healthcare- and community-associated methicillin-resistant Staphylococcus aureus at a rural hospital. Plos ONE. 2012;7, e38354.

22. Maslow JN, Mulligan ME, Arbeit RD. Molecular epidemiology: application of contemporary techniques to the typing of microorganisms. Clin Infect Dis. 1993;153-162.

23. Alipour F, Ahmadi M, Javadi S. Evaluation of different methods to detect methicillin resistance in Staphylococcus aureus (MRSA). J Infect Public Health. 2014;7:186-91.

24. Mehndiratta P, Bhalla P, Ahmed A, Sharma Y. Molecular typing of methicillin-resistant Staphylococcus aureus strains by PCR-RFLP of SPA gene: a reference laboratory perspective. Indian J Med Microbiol. 2009;27:116.

25. Valour F, Blanc-Pattin V, Freydière A-M, et al. Rapid detection of Staphylococcus aureus and methicillin resistance in bone and joint infection samples: evaluation of the GeneXpert MRSA/SA SSTI assay. Diagn Microbiol Infect Dis. 2014;78:313-5.

26. van Leeuwen W, Libregts C, Schalk M, Veuskens J, Verbrugh H, van Belkum A. Binary typing of Staphylococcus aureus strains through reversed hybridization using digoxigenin-universal linkage system-labeled bacterial genomic DNA. J Clin Microbiol. 2001;39:328-31.

27. Norazah A, Liew S, Kamel A, Koh Y, Lim V. DNA fingerprinting of methicillinresistant Staphylococcus aureus by pulsed-field gel electrophoresis (PFGE): comparison of strains from 2 Malaysian hospitals. Singapore Med J. 2001;42: 015-9.

28. Ghaznavi-Rad E, Goering R, Nor Shamsudin M, et al. mec-associated dru typing in the epidemiological analysis of ST239 MRSA in Malaysia. Eur J Clin Microbiol Infect Dis. 2011:30:1365-9.

29. Welsh J, McClelland M. Fingerprinting genomes using PCR with arbitrary primers. Nucleic Acids Res. 1990;18:7213-8.

30. Tambic A, Power E, Tambic T, Snur I, French G. Epidemiological analysis of methicillin-resistant Staphylococcus aureus in a Zagreb trauma hospital using a randomly amplified polymorphic DNA-typing method. Eur J Clin Microbiol Infect Dis. 1999:18:335-40.

31. Power E. RAPD typing in microbiology - a technical review. J Hosp Infect. 1996:34:247-65.

32. Clinical and Laboratory Standards Institute (CLSI). Performance standards for antimicrobial susceptibility testing: twenty-third informational supplement M100-S23. Wayne, PA, USA, 2013

33. Zhang K, Sparling J, Chow BL, et al. New quadriplex PCR assay for detection of methicillin and mupirocin resistance and simultaneous discrimination of Staphylococcus aureus from coagulase-negative staphylococci. J Clin Microbiol. 2004:42:4947-55.

34. McClure J-A, Conly JM, Lau V, et al. Novel multiplex PCR assay for detection of the staphylococcal virulence marker Panton-Valentine leukocidin genes and simultaneous discrimination of methicillin-susceptible from-resistant staphylococci. J Clin Microbiol. 2006:44:1141-4.

35. Zetola N, Francis J, Nuernberger E, Bishai W. Community acquired methicillin-resistant Staphylococcus aureus: an emerging threat. Lancet Infect Dis. 2005;5:275-86

36. Casey A, Worthington T, Caddick J, Hilton AC, Lambert PA, Elliott TS. RAPD for the typing of Staphylococcus aureus implicated in nosocomial infection. J Hosp Infect. 2007:66:192-3.

37. Zong Z, Peng C, Lu X. Diversity of SCCmec elements in methicillin-resistant coagulase-negative staphylococci clinical isolates. Plos ONE. 2011;6, e20191.

38. Casselas J, Antimicrobial Resistance Committee. Results of the 7th survey if the Antimicrobial Resistance Committee of the Pan American Association of Infectious Diseases. Rev Panam Infectol. 2006:8:48-55.

39. Diekema DJ, BootsMiller BJ, Vaughn TE, et al. Antimicrobial resistance trends and outbreak frequency in United States hospitals. Clin Infect Dis. 2004:38:78-85.

40. Lescure F, Biendo M, Douadi Y, Schmit J, Eveillard M. Changing epidemiology of methicillin-resistant Staphylococcus aureus and effects on cross-transmission in a teaching hospital. Eur J Clin Microbiol Infect Dis. 2006;25:205-7.

41. Ponce de Leon A, Amabile-Cuevas C, Benitez A. In vitro activity of tigecycline and other antimicrobial drugs against selected pathogens isolated in Mexico. Clin Microbiol Infect. 2008;14:S611. 
42. Tiemersma EW, Bronzwaer SL, Lyytikäinen O, et al. Methicillin-resistant Staphylococcus aureus in Europe, 1999-2002. Emerg Infect Dis. 2004;10: 1627-34.

43. Brugnaro P, Fedeli U, Pellizzer G, et al. Clustering and risk factors of methicillin-resistant Staphylococcus aureus carriage in two Italian long-term care facilities. Infection. 2009;37:216-21.

44. Atilano MAG, Pena AC, Chua JA, Coronel R. Prevalence of methicillinresistant Staphylococcus aureus and methicillin-resistant coagulase negative Staphylococcus in a tertiary hospital. Phil J Microbiol Infect Dis. 2001;30:126-32.

45. Ontengco D, Baltazar L, Santiago R, Matias R, Isaac C, Tuazon A. Methicillinresistant Staphylococcus aureus isolates from Filipino patients (1999-2003). Phil J Microbiol Infect Dis. 2004;33:105-10.

46. Hsueh P-R, Chen W-H, Teng L-J, Luh K-T. Nosocomial infections due to methicillin-resistant Staphylococcus aureus and vancomycin-resistant enterococci at a university hospital in Taiwan from 1991 to 2003: resistance trends, antibiotic usage and in vitro activities of newer antimicrobial agents. Int J Antimicrob Agents. 2005;26:43-9.

47. Sauer P, Síla J, Štosová T, et al. Prevalence of genes encoding extracellular virulence factors among methicillin-resistant Staphylococcus aureus isolates from the University Hospital, Olomouc, Czech Republic. J Med Microbiol. 2008:57:403-10.

48. Liu M, Liu J, Guo Y, Zhang Z. Characterization of virulence factors and genetic background of Staphylococcus aureus isolated from Peking University People's Hospital between 2005 and 2009. Curr Microbiol. 2010; 61:435-43.

49. Sancak B, Ercis S, Menemenlioğlu D, Colakoğlu Ş, Hasçelik G. Methicillinresistant Staphylococcus aureus heterogeneously resistant to vancomycin in a Turkish university hospital. J Antimicrob Chemother. 2005;56:519-23.

50. Tsiodras S, Gold HS, Sakoulas G, et al. Linezolid resistance in a clinical isolate of Staphylococcus aureus. Lancet. 2001;358:207-8.

51. Akpaka PE, Kissoon S, Rutherford C, Swanston WH, Jayaratne P. Molecular epidemiology of methicillin-resistant Staphylococcus aureus isolates from regional hospitals in Trinidad and Tobago. Int J Infect Dis. 2007;11:544-8.

52. Kocsis E, Lagler H, Pesti N, et al. Comparison of Austrian, Hungarian and Macedonian methicillin-resistant and methicillin-sensitive Staphylococcus aureus strains in relation to prevalence of cytotoxin genes. Microb Pathog. 2009:46:328-36.

53. Szmigielski S, Prevost G, Monteil H, Colin D, Jeljaszewicz J. Leukocidal toxins of staphylococci. Zentralbl Bakteriol. 1999;289:185-201.

54. Seybold U, Kourbatova EV, Johnson JG, et al. Emergence of communityassociated methicillin-resistant Staphylococcus aureus USA300 genotype as a major cause of health care-associated blood stream infections. Clin Infect Dis. 2006;42:647-56.

55. David M, Daum R. Community-associated methicillin-resistant Staphylococcus aureus: epidemiology and clinical consequences of an emerging epidemic. Clin Microbiol Rev. 2010;23:616-87.

56. Rodríguez-Noriega $\mathrm{E}$, Seas $\mathrm{C}$. The changing pattern of methicillin-resistant Staphylococcus aureus clones in Latin America: implications for clinical practice in the region. Braz J Infect Dis. 2010;14:87-96.

\section{Submit your next manuscript to BioMed Central and we will help you at every step:}

- We accept pre-submission inquiries

- Our selector tool helps you to find the most relevant journal

- We provide round the clock customer support

- Convenient online submission

- Thorough peer review

- Inclusion in PubMed and all major indexing services

- Maximum visibility for your research

Submit your manuscript at www.biomedcentral.com/submit

) Biomed Central 